\title{
Proceeding
}

Supplementary Issue: Summer Conferences of Sports Science. Costa Blanca Sports Science Events, 20-21 September 2019. Alicante, Spain.

\section{Establishing test and determination the normative levels to measure the block endurance of youth Volleyball Players}

\author{
ABDUL ZAHR H. MIHAISIN¹, DHORGAM H. ESSA ${ }^{1}$, GHAFAR S. ESSA ${ }^{2}$ \\ ${ }^{1}$ Faculty of Physical Education and Sport Science, Walcott University College, Kut, Iraq \\ ${ }^{2}$ Faculty of Physical Education and Sport Science, Wasit University, Kut, Iraq
}

\begin{abstract}
The aim of this research establish levels of The volleyball player (youth) in test and defined levels of the players who took part in The Iraq champion ship of 2017 in the middle Euphrates Area in Iraq. To achieve the purpose of this study (50) players took part in this research, then the test is designed and two in block endurance skill are done sample from the original society. And the statistical treatment for variables of the(throw, stability and objectivity, the choice was put in the Final shape in which we can evaluate the Firmness of the repulsion wall so that the technical achieve mentis were divided into four levels ( excellent, perfect, middle , low ). Establishing test and defines standards off Volleyball block skill Endurance for youth player. Keywords: Volleyball; Players; Youth.
\end{abstract}

\section{Cite this article as:}

Mihaisin, A.Z.H., Essa, D.H., \& Essa, G.S. (2019). Establishing test and determination the normative levels to measure the block endurance of youth Volleyball Players. Journal of Human Sport and Exercise, 14(5proc), S1863-S1869. doi:https://doi.org/10.14198//hse.2019.14.Proc5.05

\footnotetext{
Corresponding author. Faculty of Physical Education and Sport Science, Walcott University College, Kut, Iraq.

E-mail: dr.ghafarsaeedissa@gmail.com

Supplementary Issue: Summer Conferences of Sports Science. Costa Blanca Sports Science Events, 20-21 September 2019. Alicante, Spain.

JOURNAL OF HUMAN SPORT \& EXERCISE ISSN 1988-5202

(c) Faculty of Education. University of Alicante

doi:10.14198/jhse.2019.14.Proc5.05
} 


\section{INTRODUCTION}

The volleyball game is one of the games which depend basically on the quick movements and depends on the bearing physical, skill full per for mince and these elements used during the transmissions between the defensive and offensive duties.

(The skills of the game are numerous the main skills are Serving, reception set up, spiking, Block and the volleyball court defence. These are related in different positions and movements during the game ) and the skill of the Block which could get points without using high physical effort from the players of the by blocked balls from the other team directly in most cases and determine the situation for the team which play high levels of the block.

The achievement of the best level of performance came in because of the develop meant of players physical components and the building of his ability to bear these components for long time according to the special programs and modern scientific measurements until they can determine the level of every players according to their ability and their strong connection with the skilful side and the skill of repulsion wall bearing so that the head full resort for this game to measure and endurance performance and the Block as many skills are subjected for testing to stand on the level of the player innovate tests that have the ability to reverse the real image for his level in this skill and other skills, so that the Cardio unclear system and muscular system which meet the light load from them and to the extent that the player can continue to perform this skill and the limits of his abilities to contribute to perform the teams plans this matter makes the coaches to use tests meet this need and work to evaluate the performance levels especially advanced players of the high levels is different from the physical building for the ordinary.

The advanced players have high proportion of performance in which the body bulk has an important role in volleyball game so that it affects the performance level of repulsion wall skill, and the per fiction of repulsion wall in the right levels of players will provide more chances to win and to fail the other teams attempts in the matches and this is the importance of this research ${ }^{1}$.

\section{METHODOLOGY}

When a volley ball team get good results and high levels because of the regulator planning training and how to face the difficult circumstances and bearing the physical and skill full performance is an important part of training procedure which helps the player to continue playing in the match and for a perfect performance comparatively for a long time and endurance the circumstances which facing him during the competition.

The high levels players have different physical muscular fitness and their performance in another levels especially endurance component. The Block one of the skills which needs for high bearing performance makes the researchers design test to measure bearing performance of Block and find normative levels for youth in this game for which the coach can direct and develop his training program to do the best results and achievements.

\section{Research Goals}

1- Make test to measure the Block endurance Performance for volleyball on a sample for this research.

1 Bandypadhyay .A. (2007) ; Anthropometry and Body composition in Soccer and Volleyball players in west Bengal , Lydia . p 501505. 
2- Put normative levels to measure the level of the Block endurance Performance for volleyball for a sample for this research.

\section{Research Domain}

1- Population Domain. The players of the south area clubs (youth) in volleyball in season (2017-2018).

2- Period of Time Domain (1-11-2018 - 24- 12- 2018)

3- Locative Domain. The sport halls that belong to this research.

\section{Research Method and procedure}

The researchers used the descriptive method to solve the problem.

\section{Participants}

The research community represented by the club players of the Middle Euphrates Area (youth) for volleyball in season (2017-2018) they are (96) players. And the research chose the research sample in random method and distributed them on all the areas of the south area who were (50) players in rate $(52 \%)$ from the original community.

\section{Measures}

- $\quad$ Test and measurement.

- Legal volleyball court.

- $\quad$ stopwatch, whistle, measuring tape, balls holder, volleyballs, rubbery rope.

- $\quad$ The Arabic foreign sources and references.

\section{Procedure}

After reading the scientific sources and the researches which related to the volleyball and dependence of the expert's opinions. The test was designed to measure the Block Skill in durance level in volleyball (youth) so that they built and designed the test and determined the necessary conditions its special instructions and the recording method.

\section{Test for measuring Block Skill in durance level in volleyball}

The Aim of the test

To measure the Block Skill in durance level in the volleyball (youth).

\section{Tools}

Legal volleyball court, volleyballs, stopping watch, whistle, ball holder, rubbery rope and columns with (150 $\mathrm{cm})$ length and $(50 \mathrm{~cm})$ width from net level.

\section{Test Specifications}

The volleyball court must be drowned and lined as in figure (1):

The Sample stand s on the side line near the number (2) centre and starts to perform the Block at the number (2) position then performs Block from the number (3) position then from number (4) position then he comes back to perform the Block from (2) and (3) position and starts very quickly from the side line the end of the court in the point where the side line meets the final line, then starts on the final line and side line to return to the beginning point and repeats the performance three times. 


\section{Recording Method}

Points Record from times which the tested player has in extreme Block endurance during the (3) attempts

\section{Exploratory Experience}

The researchers did their exploratory experience on the young volleyball players from waist province they were (8) players in 5-12-2018 and the aims of the experience were;

1- Deter mine and fix the distance of the test.

2- Determine the required time to the perform in Block in durance skill test in volleyball.

3- Know the obstructions that happened during the test.

4- Know how to count the attempts and mistakes happened to the player.

5- Know the height of the ball's holders from the net level.

The scientific bases to build and determine the normative levels of the test:

To regard the scientific bases of designing and rationing the suggested test from the researchers and to get on these bases:

The researcher showed the test on a group of experts and complements in the fields of testing measuring and volleyball to know the test sincerity and from the experts opinions the test was found sincere to measure the required aim and give some notes on the its surrounding circumstances ( supplement (1) ).

To find the stability factor to do the test on (20) players from the same community in 16-12-2018 on Sunday then the test was repeated after a week under the same circumstances.

Then the simple connection factor was counted between both tests and compared this with the tabular value of the freedom degree (19) significance level (0.05).

The stable test is the test which has a high degree of accuracy, perfection , consistency and objectivity for its measurement if it is found the calculated value for the test is bigger than the tabular value this will ensure that the test has high value of stability and moral signify cancer connection as in the table (1).

Table 1. Show the stability coefficient of the suggested test

\begin{tabular}{lll}
\hline Significance & Stability coefficient & Test \\
\hline moral & 0.91 & $\begin{array}{l}\text { The bearing performance of the } \\
\text { repulsion wall of volleyball }\end{array}$ \\
\hline
\end{tabular}

The value of $(R)$ tabular of stability coefficient under the significance level (0.05) and the temperature (19).

The test was displayed on a group of experts and competent in testing, measurement and volleyball and they assured the test is clear and easy to understand and it is unexplainable it has objective correction not subjective as well as the unit of the test measurement (time). These things bestowed a high degree of objectivity on this test.

The main experience

After finishing from the stage of test building and extract the scientific basis the researchers performed the main experience on test sample which was the players of the Middle Euphrates Area in the Iraqi league 
(youth) they were (50) players on the rate ( 52 ) \% from the original community for the season (2017-2018) for completion the requirements of the test goals and extract nor motive levels.

\section{Statistical means ${ }^{2}$}

1- Mathematical mean.

2- Nor motive diversion.

3- Percentage.

4- simple connection element.

5- Normative levels.

\section{DISCUSSION}

Put standards and extract the normative levels to test the bearing performance of crushing hitting in volleyball.

Measuring standards are used to determine the relativity case of the crude points to explain these points and correct their results ${ }^{3}$. The standards were not obsolete or stable but they were relativity and depend principally on certain reference groups and these standard are affected a great effect when the characteristics of these groups which compared with individual in a specific trait or group of traits which the test measured are changed when the individuals of the results of the standards deriving for the testing of bearing performance of repulsion wall in volleyball were divided into division that near to the normal division ,so that the researchers decided to determine the standards in the adjusted second degree method as well as the statistical mean was $(40,64)$ degree and the normative deviation was $(3,92)$ degree and the table $(2)$ shows the crude points for the individuals of the standards deriving sample for teat bearing performance of repulsion wall in volleyball.

Table 2. Show the crude normative degree for individuals of deriving standards for bearing test of repulsion wall of volleyball.

\begin{tabular}{cccccc}
\hline Modified normative degree & Crude degree & $\mathrm{N}$ & Modified normative degree & Crude degree & $\mathrm{N}$ \\
\hline 0.3 & 42 & 9 & $1.6-$ & 34 & 1 \\
0.6 & 43 & 10 & $1.4-$ & 35 & 2 \\
0.8 & 44 & 11 & $1.1-$ & 36 & 3 \\
1.1 & 45 & 12 & $0.9-$ & 37 & 4 \\
1.3 & 46 & 13 & $0.6-$ & 38 & 5 \\
1.6 & 47 & 14 & $0.4-$ & 39 & 6 \\
1.8 & 48 & 15 & $0.1-$ & 40 & 7 \\
2.1 & 49 & 16 & 0.09 & 41 & 8 \\
\hline
\end{tabular}

It must contain degrees show the necessary true level of individual from the high, middle and low levels and because many characteristics and adjectives are measured in the physical education field which approach from the normal distribution in spread so that the researchers must use the normal distribution in it . The researchers put four levels (perfect, good, middle, weak); since the suggested tests are measured in degree namely whenever the lab collecting of degrees increased, this means the performance level of this skill would be high.

\footnotetext{
${ }^{2}$ Abdal Rahman Adas ; The Principles of Counting in Education and Psychology p.2. AlAqssa library . Oman 1981.

3-Mahmud Shuber and other ; The placement of Nor motive levels for testing Physical Abilities. Educational Sciences Magazine 2005.
} 
The levels and their treatments were put by putting correction limits which met each level as well as there was extension of the number of repletion and percentage as in the table (3).

Table 3. Show the normative levels test the bearing performance of repulsion wall for volleyball.

\begin{tabular}{ccccc}
\hline Percentage & Number & Level & Normative degree & Crude degree \\
\hline$\% 18$ & 9 & perfect & $0.9--1.6-$ & $37-34$ \\
$\% 46$ & 23 & good & $0.09-0.6-$ & $41-38$ \\
$\% 20$ & 10 & middle & $1.1-0.3$ & $45-42$ \\
$\% 16$ & 8 & weak & $2.1-1.3$ & $49-46$ \\
\hline
\end{tabular}

\section{RESULTS}

The result of the test of bearing performance of repulsion wall in volleyball (youth) were determined in four levels the first level (perfect) was in repetition (9) and the percentage was (18\%). This show that the most repetition for level of the sample was in the second level (good) was in repetition (23) and the percentage was (46\%) after that the third level (middle) was in repetition (10) and level ( weak) came in repetition (8) and the percentage was (16\%) from the sample results table which the test showed the results were divided on four levels each level represent a part from the sample and determine the level of the bearing performance of repulsion wall in volleyball according to the level which represented it then it gave a clear signal for the coach and the player on the players levels limits in the efficiency function of the berating and rotation systems to extend the muscles with food and oxygen and fast disposal of refuse which was resulted from effort. The muscles cannot continue to work without getting food and oxygen which are conveyed to the cells by the breathing and rotation systems and the coach must build his work plan in the subject of players preparation according to standards and levels and should prepare training program according to the levels which the player proposed in the test on the extent of the placed plan as in the experimental mat chess and competition.

\section{CONCLUSIONS}

1- The level of the individuals of the sample in the test of Block Skill in durance level in volleyball located in tow levels (perfect and good) and formed a rate $(18 \%, 46 \%)$ respectively.

2- The test of Block Skill in durance level in volleyball is commensurate with the level of the sample individuals.

3- Design four normative levels (perfect, good, middle, weak).

\section{RECOMMENDATIONS}

1- Recommend using the normative levels of the research to evaluate the players levels of Block Skill in durance level in volleyball.

2- Give Block atop importance in drawing the special training program for the volleyball players.

\section{REFERENCES}

Abdal Rahman Adas; The Principles of Counting in Education and Psychology p.2. AlAqssa library . Oman 1981.

Bandypadhyay .A. (2007) ; Anthropometry and Body composition in Soccer and Volleyball players in west Bengal. 
Salah Aldeen Mahmod Alam ; The Educational and psychological measurement and correction of its contemporaneity applications and fundamentals. Cairo , DarAlfiker Al-Arabiya 2000.

Muhamed Subhi Hasanin ; The Practical Analysis For the Physical abilities in the Fields of Physical and sports Education E.2. Cairo . Dar Al Faker Al-Arabiya 1996.

Mahmud Shuber and other ; The placement of Nor motive levels for testing Physical Abilities . Educational Sciences Magazine 2005. 